\title{
The architecture of spectacular buildings in the city of Kazan in the context of national and regional traditions
}

\author{
Natalia Kinosyan ${ }^{1[0000-0003-0837-6566]}$, and Elza Bashirova*1[0000-0002-0346-1713] \\ ${ }^{1}$ Kazan State University of Architecture and Engineering, 420043 Kazan, Russia
}

\begin{abstract}
The specificity of the formation of facade and spatial solutions of large spectacular buildings in Kazan is considered in the context of national and regional traditions. Ornamental and decorative systems, adapted to the architectural and artistic styles that existed in this period were identified. The main approaches to the design of large spectacular buildings in the context of national and regional traditions in the architectural practice of Kazan in the middle and the end of the XX century were identified as follows:

- based on the use of the dominant styles in the considered periods (classics with the ideological concept of socialism, modernism, postmodernism), adapted to the architectural traditions of the decorative system of the Middle Volga region; - based on the use of modern finishing materials - ceramics, majolica, natural stone, which has references to the traditions of facing the facades of Bulgar buildings with limestone and glazed tiles. The architects of the middle and the end of the XX century laid the foundations of modern regional-national architecture and the methodology for the formation of a decorative-artistic system that combines the stylistic techniques of classicism, modernism, postmodernism with techniques which had references to the Bulgar-Tatar traditions.
\end{abstract}

Keywords. Spectacular buildings, theaters, national and regional traditions in architecture, ornamental complexes in architecture, architecture of the Middle Volga region, regional architecture.

\section{Introduction}

The objects of study were spectacular buildings located in the central part of the city of Kazan:

- Tatar Academic State Opera and Ballet Theatre named after Musa Dzhalil (2, Svobody Square, 1948-1956, architects: N. Skvortsov, I. Gainutdinov);

- Galiasgar Kamal Tatar State Academic Theatre (1, Tatarstan St., 1972-1982, architects:

G. Gorlyshkov, M. Agishev, Y. Korneev, F. Evseev);

- Saydashev State Great Concert Hall (3, Svobody Square, construction - 1967, architects:

M. Agishev, E. Agisheva, reconstruction - 1996, architects: V. Loginov, E. Prokofiev, V. Abramov).

In the modern architectural practice of Kazan, the problems of globalization appear more and more often. Recently, in the conditions of the intensive development of the capital of the

${ }^{*}$ Corresponding author: bashirova.arch@gmail.com 
republic, issues related to the problem of attitude to heritage are of great relevance. Also, researchers recognize the need to create a scientific base for the formation of modern architecture of the Republic of Tatarstan, which has features of cultural identity. The middle and the end of the XX century is an important period when the foundations and scientificpractical approach to the modern understanding of regional architecture in different style systems were laid. Therefore, this period is considered in this study.

The objectives of this study:

- identification of archival and natural sources on the stated topic;

- analysis and systematization of research materials;

- identification of design techniques used in large spectacular buildings in the architectural practice of Kazan in the middle and the end of the XX century in the context of national and regional traditions. The study of these techniques on the example of the considered objects.

Despite the fact that the national-regional traditions of a particular region represent a complete set of architectural techniques, forms and motifs, their interpretation and application in architecture can be varied and the attitude towards them can vary depending on the period. The second half of the XX century is characterized by the increased interest in national and regional traditions. Particular attention is paid to the preservation of historical authenticity during restoration $[1,2]$. In different countries during this period, the tendencies of using national and regional traditions in the design, their comprehension and adaptation were formed. In particular, one can consider such theoretical directions as critical regionalism $[3,4]$, symbiotic architecture [5]. In both cases, the use of traditional motifs in modern architecture is not limited only to copying single elements, but is perceived as a complex representation of the entire object, including its role in the urban environment, spatial composition, detailing of the facade, interior design, social and cultural and symbolic significance of the object, etc. [6,7]. Traditional motifs in architecture are considered as the most sustainable, since they are formed in the context of a particular region, therefore they are the most effective in its conditions $[8,9]$. Thus, considering the relevance of the concept of sustainability today, we can say that the border between traditional and modern architecture is blurring, these two concepts are no longer opposites [10, 11].

The problem of national and regional authenticity is relevant for the city as a whole. The most significant tasks are to preserve the uniqueness of the urban environment and provide a comprehensive visual perception of historical cities in modern conditions [12-14]. Spectacular buildings have always been compositional and semantic dominants in the structure of the city. It is these objects that are designed to express the identity of the region, reflect the interests of local residents [15]. Very often, a reference to national and regional traditions was chosen as the basis for the imaginative solution of spectacular buildings, since they most fully reflect the nature of local architecture and culture in general at all levels, including aesthetic and symbolic. During the reconstruction of spectacular buildings, various tasks are solved, both related to the figurative solution [16] and the symbolism [17, 18], and quite technical ones, related to acoustics or ensuring fire safety $[19,20]$. One of the key national and regional historical traditions in the architecture of Tatarstan is the use of ornamental complexes in the design of details of the facade and interior of buildings. The ornamental tradition began to develop in the pre-Islamic period, and later, in the Islamic period, reached its maximum development, combining the influence of Arab countries and Tatar folk traditions [21]. Arab countries are characterized by the predominance of geometric ornament $[22,23]$, there are also motifs related to weaving [24]. Tatar folk traditions are characterized by the most frequent use of plant motifs, reflecting the beauty of the nature of the Middle Volga region, less often - geometric and zoomorphic motifs [25]. 


\section{Materials and methods}

The research methodology is based on a comprehensive analysis, which includes historical and architectural, literary, archival analysis, field survey and comparative architectural and design analysis. Within the framework of the historical, architectural and literary analysis, the periodization of the architecture of the Middle Volga region is considered from the point of view of the formation of architectural and urban planning types, stylistic features, the development of the decorative system of the Middle Volga region, which were addressed by the practicing architects of Kazan in the middle and the end of the XX century. The main features and ornamental complexes, which became the basis for the facade solutions of spectacular buildings in Kazan, were considered.

As part of the archival analysis, the author's sketches, drawings and historical photographs of fragments of facades and interiors of objects were revealed. A full-scale examination includes a visit directly to the object and photographic recording of its current state.

As part of a comparative architectural and design analysis, the processing and systematization of the collected documents were carried out, the influence of regional architectural traditions on the facade and space-planning solution of the considered spectacular buildings of Kazan was revealed.

\section{Results and discussions}

Since the middle of the XX century, practical architects of Kazan have been deeply studying the regional architectural heritage and the possibility of using traditions in the modern architecture of large public buildings. The uniqueness of the architecture of the Middle Volga region lies in the fact that at different stages of development the region was influenced by two large civilizations - European and Asian. The main stages of its development are distinguished in the architecture of Tatarstan: pre-Islamic (from early antiquity to the end of the IX century); Islamic (from the end of the IX century to the middle of the XVI century); Islamic-Christian (from the middle of the XVI century to the beginning of the XX century); modern (from the beginning of the XX century). Each of the periods is characterized by: the structure of the architectural space organization, the system of urban planning and spaceplanning types, stylistic and compositional features, the dynamics of the cultural interaction.

In the pre-Islamic period, «the substrate of the architectural culture of the region was formed, as a system of types with a minimal social, functional and aesthetic program, necessary and sufficient for the survival of a particular culture in the Middle Volga region (dugouts, semi-dugouts, type of open natural prayer, type of settlement: fenced quarter with a centric-cumulus arrangement of dwellings; linear arrangement of dwellings)» [21].

During the Islamic period, architectural systems were developed under the influence of patterns characteristic of the world centers of Islam. Subsequently, they were adapted to the cultural and geophysical space of the Middle Volga region: cities of cape and plain type, types of Middle Volga mosques, types of stone and wooden houses, public buildings. The influence of Islam in the natural and cultural conditions of the Middle Volga region formed their own aesthetic version - not a frozen ornamental beauty, but living techniques of plant and geometric ornaments, characterized by a light and unfinished figurative structure. The ornamental decoration of the buildings was distinguished by the following points:

- the ornament did not cover large areas of buildings;

- the ornament was overwhelmingly floral, not geometric;

- the fragmentary use of ornament served as an accent in the compositionally important parts of the facade (pediments, capitals, cornices, niches, etc.). 


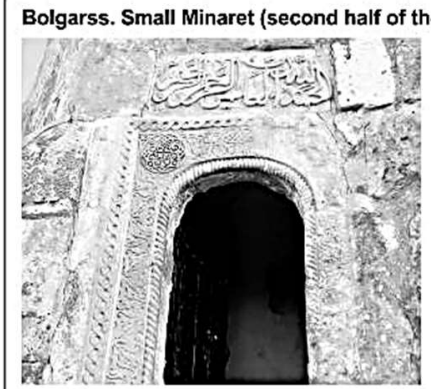

The first complex includes:

Motives: zigzags, dovetail, straight lines, triangles, squares, rhombuses, circles.

The main types of compositions: tape, radial.

Kazan. Mardzhani Mosque (stucco ornamentation of the ceiling in the main hall, 18 th century).

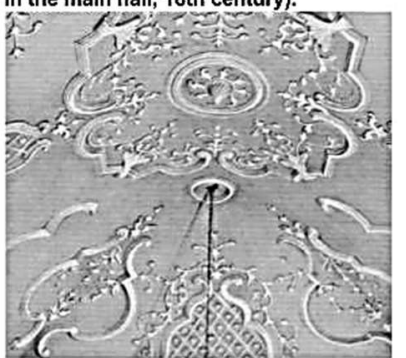

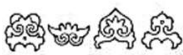

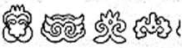
ई 还路

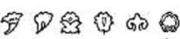

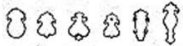
एक

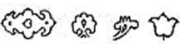

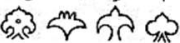

\section{The third complex includes:}

Motives: tulip, shamrock, plant leaves, lotus, heart-shaped motif. The main types of compositions: ribbon, heraldic

\section{Old Menger settlement in Arsk district (XVI century). Tombstone} (fragment of the front side)
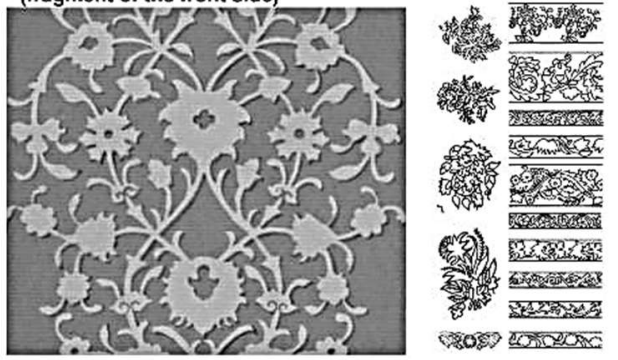

The fifth complex includes:

Motives: flowers of steppe, meadow and garden origin.

The main types of compositions: ribbon, bouquet.

\section{An architectural monument of the Kazan Tatars (Arsk district,} 18 th century, stucco ornamentation of the small hall)

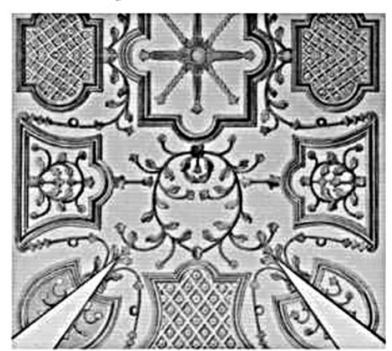

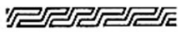

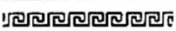

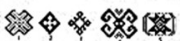

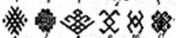

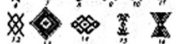

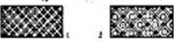

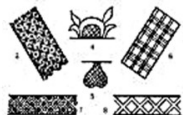

The seventh complex includes:

Motives: of zigzags, dovetail, triangles, jagged squares, rhombuses. The main types of compositions: border, mesh.

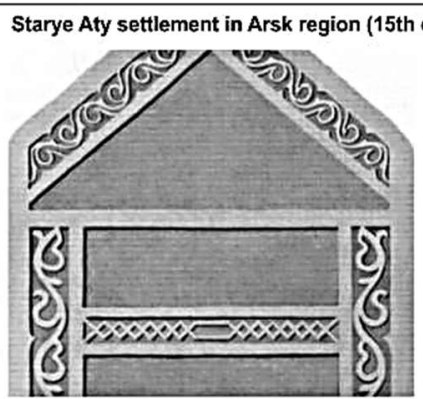

The second complex includes:

Motives: spirals, staples, oncoming waves.

The main types of compositions: tape, central beam

Bolgars. Black Chamber, fragment of the interior (XIV century)

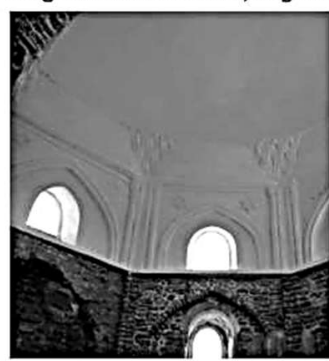

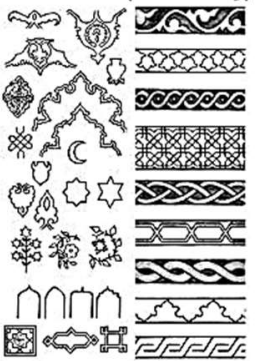

The fourth complex includes:

Motives: six and eight-pointed stars, elongated rosettes with scalloped edges, strings, braids.

The main types of compositions: ribbon, heraldic

Residential building, suburb of Kazan (XX century) Fragment of window frames
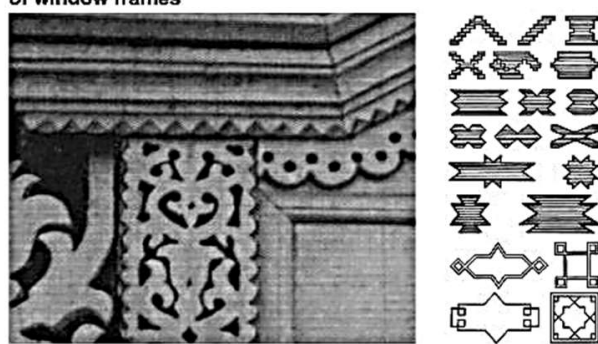

The sixth complex includes:

Motives of stepped triangles, rhombuses, polygons with inscribed figures,

The main types of compositions: border, mesh.

\section{Residential building, suburb of Kazan ( $X X$ century).}

Fragment of platbands

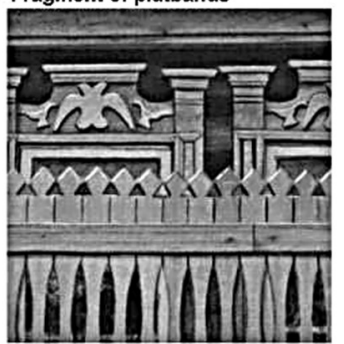

\%का exs ars 经

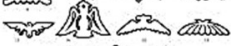

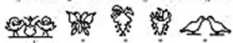

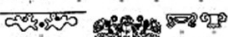

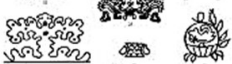

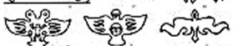
त

The eighth complex includes:

Motives: zoomorphic images in the form of paired or two-headed birds, horses.

The main type of compositions: heraldic

Fig. 1. The main historically formed ornamental complexes in the Tatar ornament. 
According to the research of F.Kh. Valeev, 8 main historically formed complexes (Fig. 1), consisting of motifs related in origin and formed in the pre-Islamic and Islamic historical periods, can be distinguished in the Tatar ornament [25]. Each complex has its own characteristics associated with the technique of execution and regional materials.

The Islamic period was divided into two successively developing states - the Volga Bulgaria and the Kazan Khanate. The stylistic features of the Volga Bulgaria were a large scale of architectural forms, rough plasticity of the masses, a small degree of detailing and decorative processing. During this period, new types of public buildings appeared: centrically-domed and centric-hipped, as well as new methods of decorative finishing of buildings were formed: the use of glazed tiles, plaster, stone carving, gypsum, wood. The architectural style of the Kazan Khanate was characterized by the formation of new compositional techniques: a combination of quadrangular volumes, octagonal volumes, a system of keeled and pointed arches. The following tendencies are formed in the decorative system: the tradition of polychrome cladding of buildings with tiles was preserved, while the techniques of applied decor and wall plastering (cornices, belts, additional columns, pilasters) were developing. The general trend was the improvement of the existing space-planning types towards a decrease in size, compactness, decorative detailing.

In the Islamic-Christian period, the introduction of Russian-European architectural and urban planning traditions took place. The features of the Pskov, Novgorod, Moscow and Vladimir-Suzdal architectural schools dominated the appearance of Kazan, but developed under the associative influence of the architecture of the Kazan Khanate. Russian Orthodox tradition has experienced counter the influence of Islamic culture. A characteristic feature of the associative commonality of Russian stone structures with Tatar architecture during this period was the use of brick stalactite ledges and tile inserts in the decorative design of the facades.

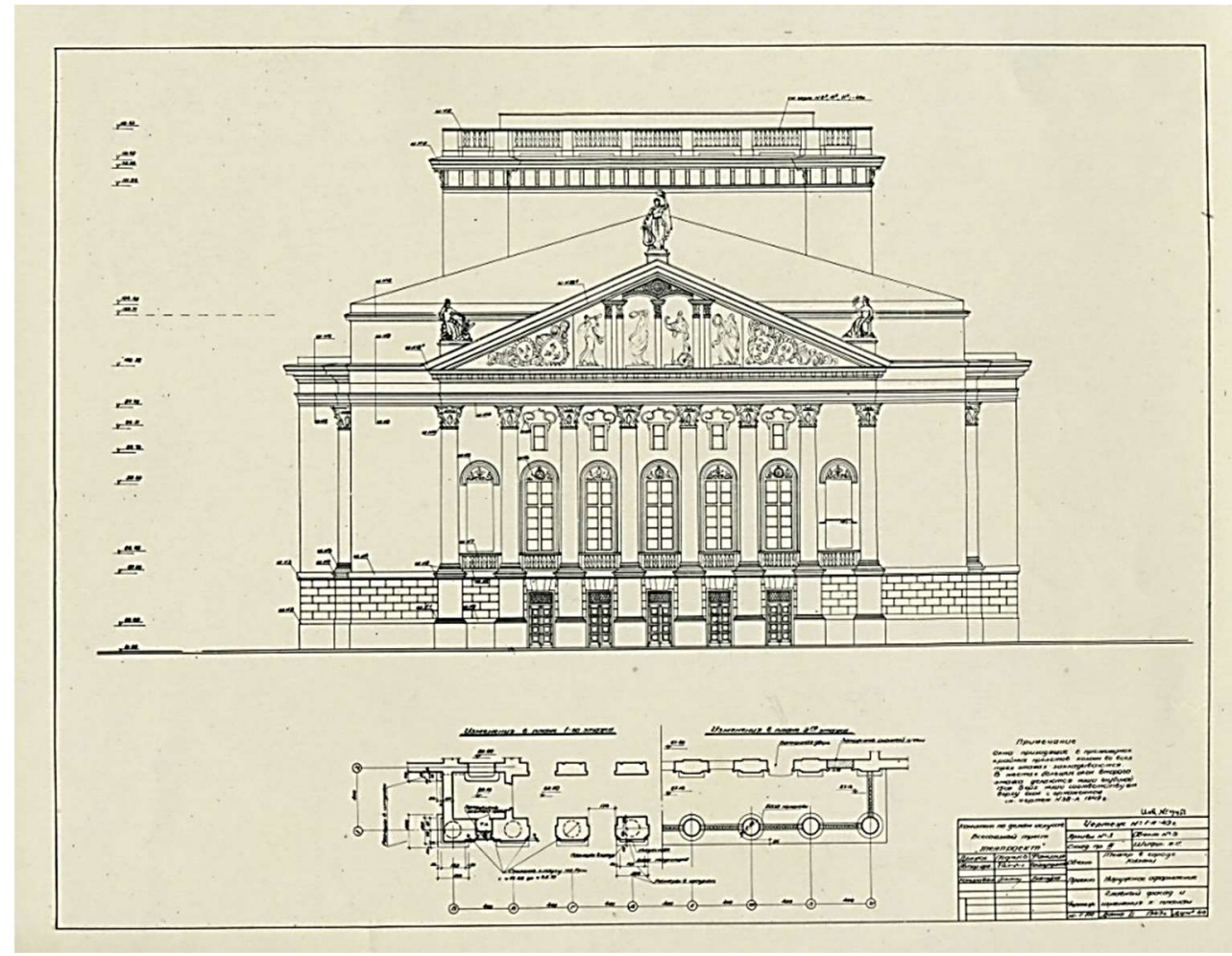

Fig. 2. The main facade of the Tatar Academic State Opera and Ballet Theatre named after Musa Dzhalil. 
The modern period (XX century) was characterized by new, replacing each other architectural stylistic trends: constructivism, neoclassicism, modernism, postmodernism. At the initial stage, the constructivism style appeared in Kazan, but it did not become widespread. By the middle of the XX century, the architecture of public buildings again began to use the forms of Russian and European Baroque, Classicism and local national stylistic trends.
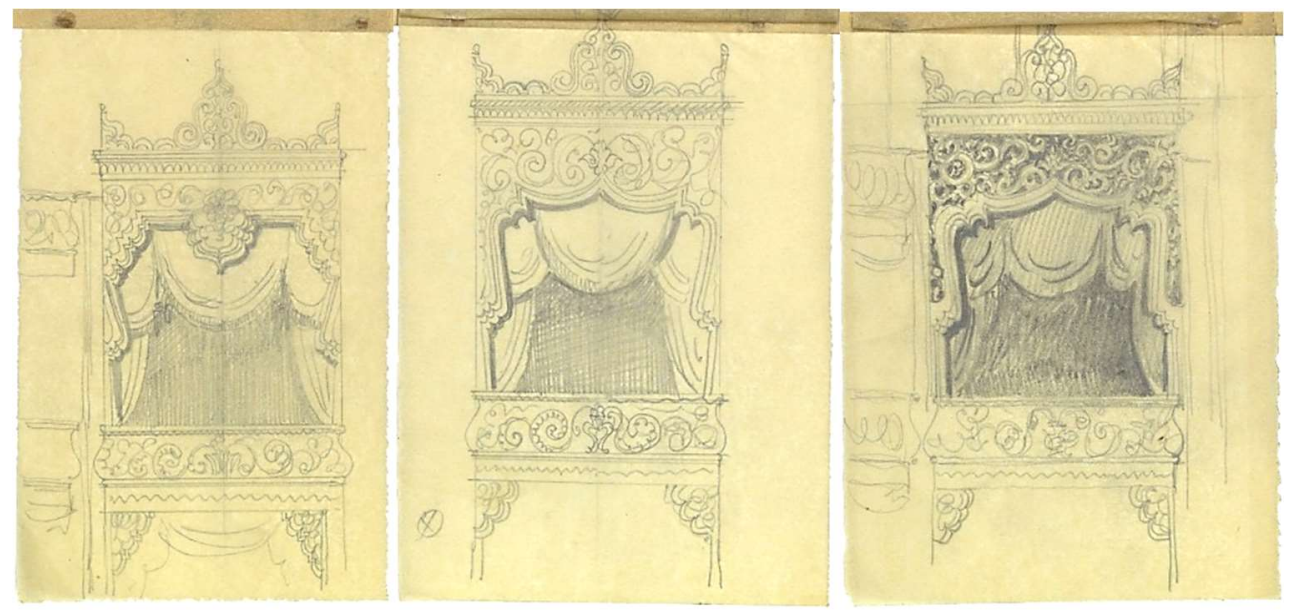

Fig. 3. Sketches for the decoration of the balconies of the Tatar Academic State Opera and Ballet Theatre named after Musa Dzhalil (1948, pencil, tracing paper). Author I.G. Gainutdinov.

Tatar Academic State Opera and Ballet Theatre named after Musa Dzhalil (1948-1956, architect I. G. Gainutdinov) has become a striking example of the implementation of a unique synthesis of the classical form and motifs of Tatar monumental architecture in Kazan which is a cultural monument of the republican level (Fig. 2) [26]. This object is distinguished by a variety of Tatar national forms of architecture and ornamental complexes (Fig. 4). A rich collection of finely traced ornaments made according to special drawings and executed in plaster, bronze, wood demanded from the architect many years of scientific work on a comprehensive study of historical Tatar architecture and art. In terms of urban planning, the theater building is one of the largest structures in Kazan and the compositional center of the city's main square (Svobody). The architecture of the theater is built on classical principles, but with the corresponding introduction of highly artistic ornamental decor in the compositionally important parts of the building (pediment, cornice, column capitals, framing facade niches and openings). The creative method that guided the theater architect is a unique synthesis of the classical architectural heritage and national shaping methods. The introduction of the ornamental complex on the facades and interiors of the building was carried out in accordance with the historical formation of the decorative system of the Middle Volga region (the fragmentary use of predominantly floral ornamentation served as an accent in the compositionally critical parts, giving a new quality to the classicist designs). The archive contains historical photographs, author's sketches and templates by architect I.G. Gainutdinov (Fig. 3, 5) [27]. In the perception of the main facade of the theater, the main visual accent is on the sculptural composition of the pediment of the main portico - a compositional facade technique of a traditional Tatar house, where the principle of the richest design of the pediment in comparison with other elements of the facade was historically applied (Fig. 3). The methods of semicircular design of niches and openings on the side facades and the division of the facade planes go back to the Bulgar-Tatar architectural forms. 

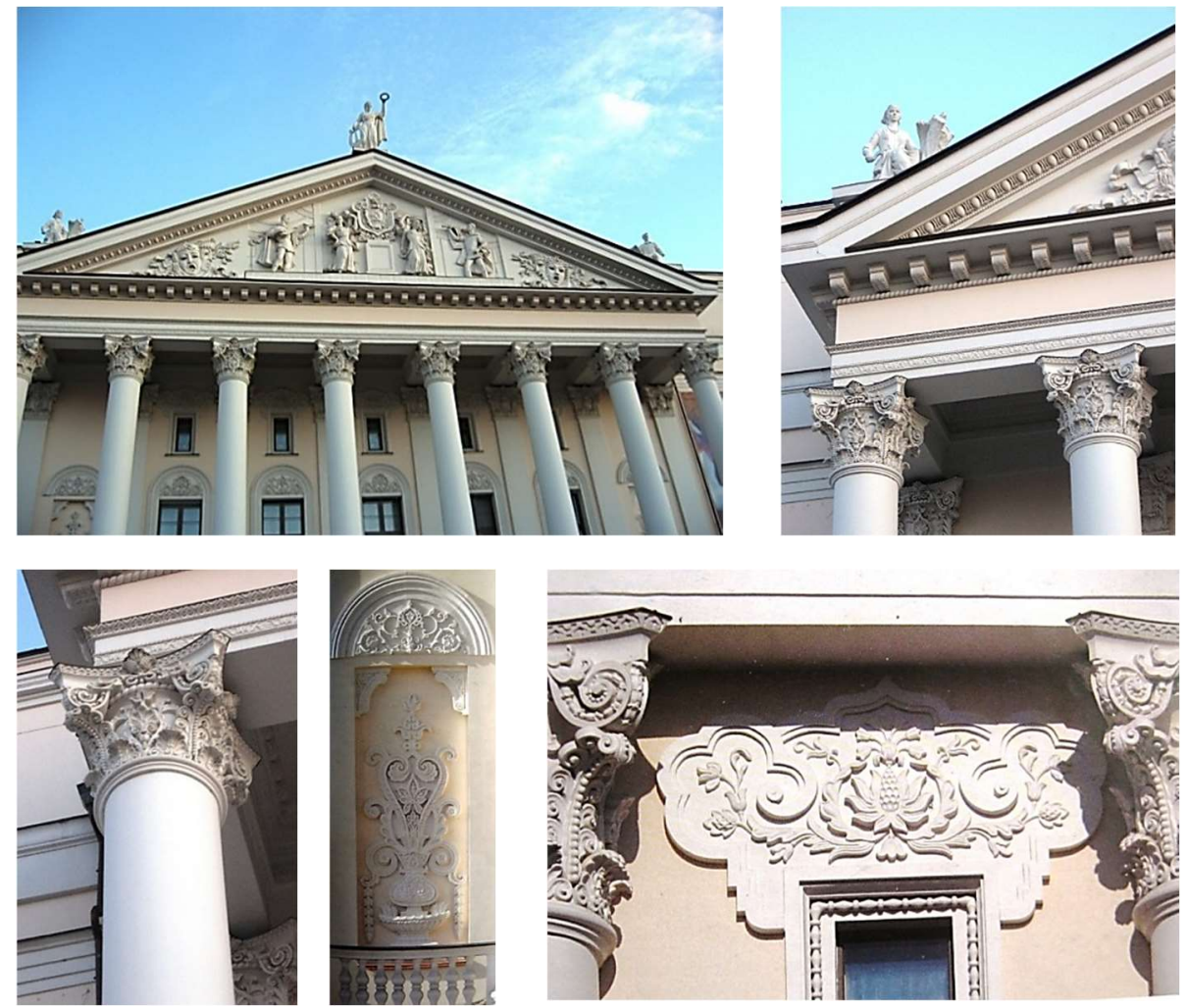

Fig. 4. Tatar Academic State Opera and Ballet Theatre named after Musa Dzhalil. Architectural and artistic elements of the facade.

An important décor-forming principle of the formation of the theater's exterior and interior is a highly professional drawing of details, reminiscent of ancient Tatar stone carving. The introduction of a complex of Tatar ornament into the elements of the classical order system, on the principles of which the building was built, was carried out delicately, almost imperceptibly for an unprofessional eye. An example is the capitals of the Corinthian order, the acanthus of which is built in the motifs of the "vine» of the Tatar ornament and the entablature, in the architrave of which the reliefs of the Tatar ornament in the motifs of the «trefoil» are introduced (Fig. 4). The most common types of ornamental compositions are ribbon, heraldic, mesh, central beam, frame. The most common motifs used within the framework of these compositional solutions are the «vine» motif, the «trefoil» motif, the «tulip» motif, the «carnation» motif, the «plant leaves» motif, the «rosette» motif and the linear geometric motif. For example, the motifs of the «vine» in combination with the motifs of the «plant leaves» were used in the design of the facade niches and in the interior of the building. The «trefoil» motif is used in the artistic metal railings of the interior staircase (Fig. 5), in the architrave of the portico; motifs of «tulip» and «carnation» framed by window openings on the facade (Fig. 4); the «lotus» motif is used in the design of the columns and railings of the main staircase in the interior (Fig. 5); geometric motifs are applied in the ceiling, accentuating the beauty of the lighting fixtures (Fig. 5). Mostly in the building of the theater, ornamental motifs of plant origin are used, corresponding to the third and fifth historical ornamental complex, less often to the second and fourth. 

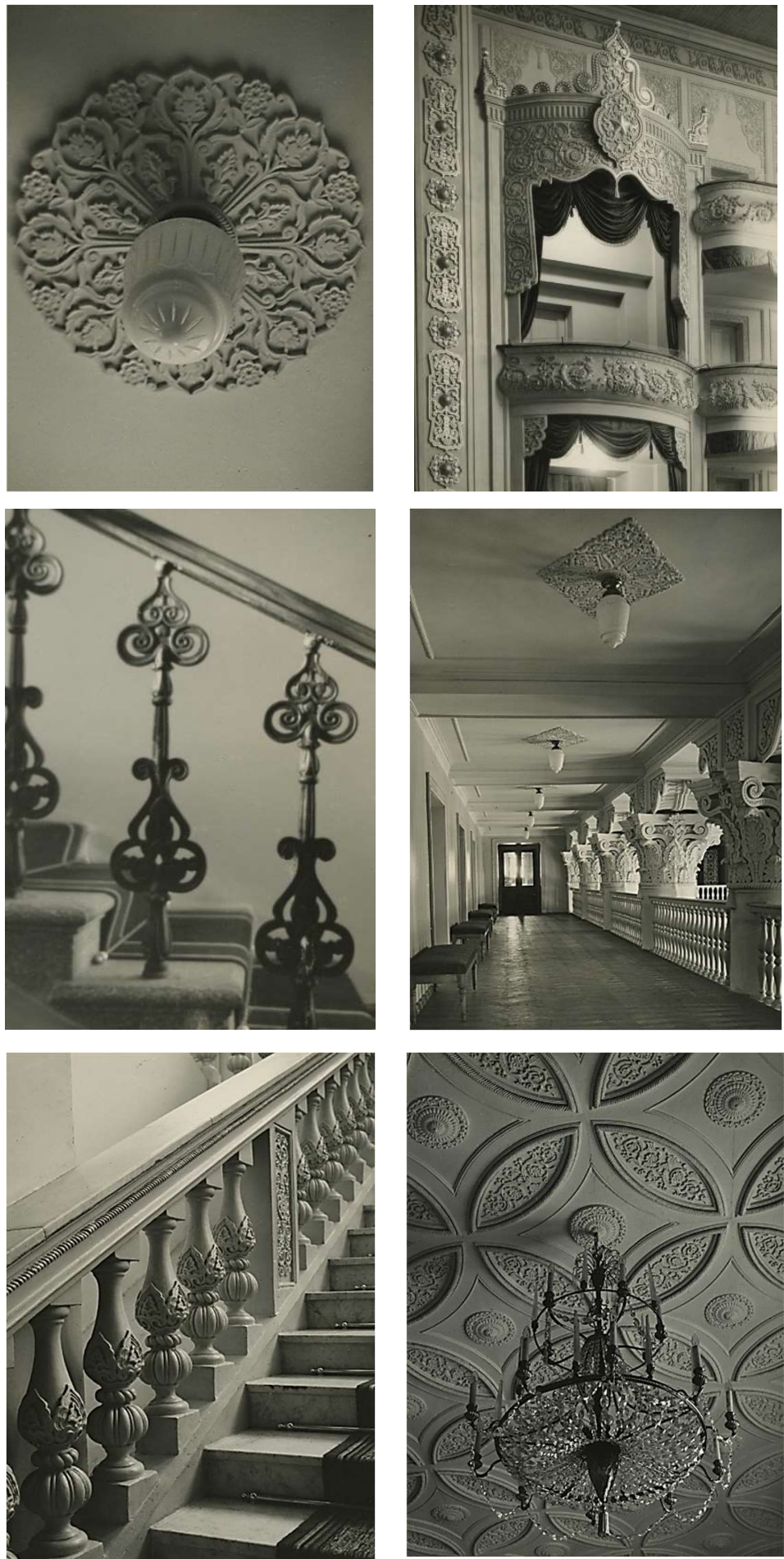

Fig. 5. Tatar Academic State Opera and Ballet Theatre named after Musa Dzhalil. Architectural and artistic elements of the interior. 
Another landmark object that combines in its image modernist methods of shaping with elements of traditional Tatar ornament and certain forms of traditional architecture in the design of the facade and interior is the Galiasgar Kamal Tatar State Academic Theatre, built in 1972-1982. according to the project of the Moscow architects G.P. Gorlyshkov (head of the team), Yu.A. Korneev, F.M. Evseev, with the participation of the chief architect of Kazan, M.Kh. Agishev (Fig. 6) [28].

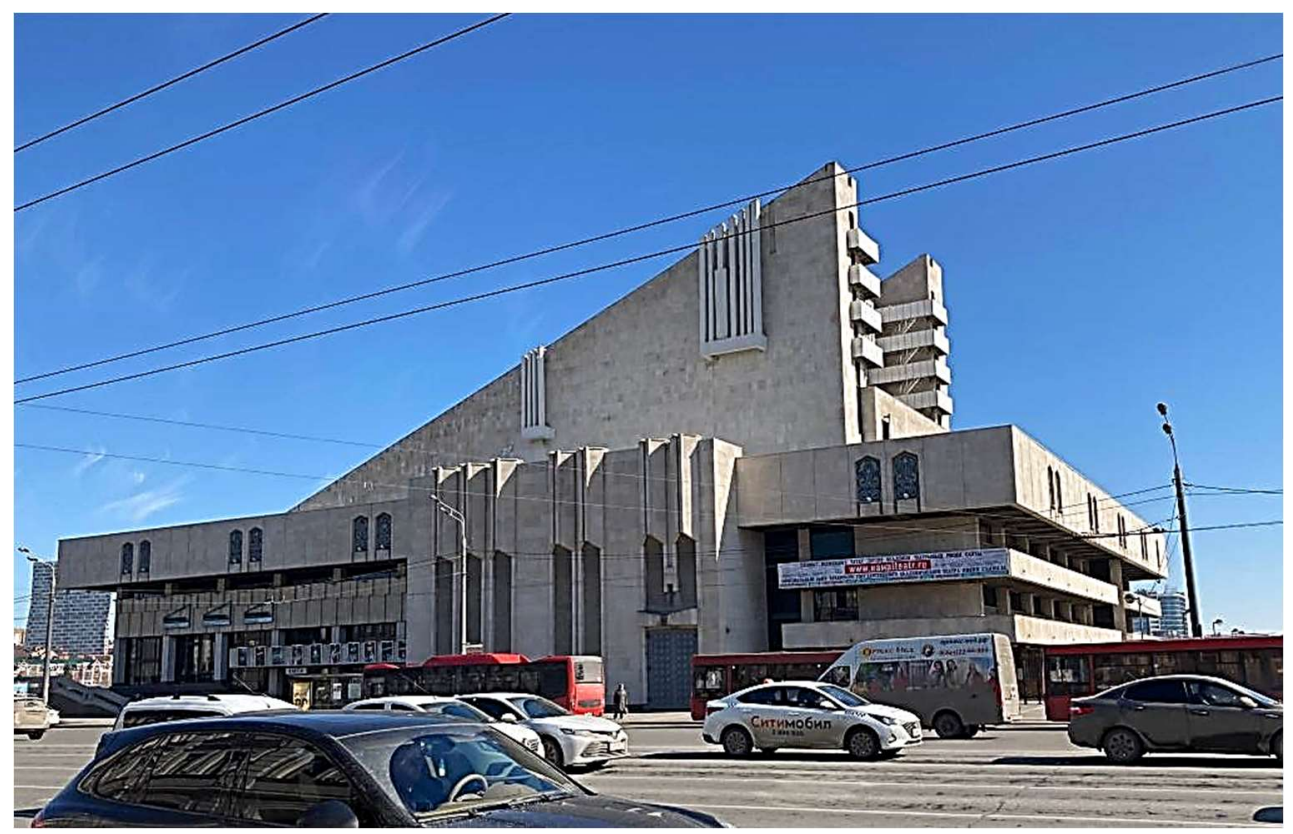

Fig. 6. Galiasgar Kamal Tatar State Academic Theatre. Exterior.

A typical design of a spectacular building was taken as the basis for the planning solution, and the basic principle of shaping was adopted in the spirit of modernism with symbolic references to the image of a ship due to the location of the building on the shore of Lake Kaban [28]. The theater building demonstrates the appropriate fragmentary interspersion of Tatar national ornamental complexes into the general artistic composition of the building, as well as the use of traditional materials and colors to highlight compositional and semantic accents, against the background of the meager decoration typical of modernism.

The responsible urban planning position of the building has determined the increased requirements for its expressiveness. It is no coincidence that the elements of modernist architecture that largely determined the architectural and stylistic appearance of Kazan at that time, references to the natural component - Lake Kaban and the corresponding introduction of elements of Tatar ornamental decor in detail were synthetically intertwined in the image of the building [29]. This example once again demonstrates the organic and artistic unity of the dominating style with national and regional traditions, inherent in the architecture of the Kazan Tatars.

The synthesis of modernist and national methods of shaping can be called the main creative method that guided the architects of the theater. The introduction of an ornamental complex of Bulgar-Tatar origin in the form of mosaic inserts on the facades (Fig. 8) and stylized "white stone» ornamented panels on the walls, forging, inlaid on leather, mosaics used in the interior of the building (Fig. 7) was carried out in accordance with the historical formation of the decorative system of the Middle Volga region (fragmentary use of predominantly floral ornamentation served emphasis in compositionally critical parts). 

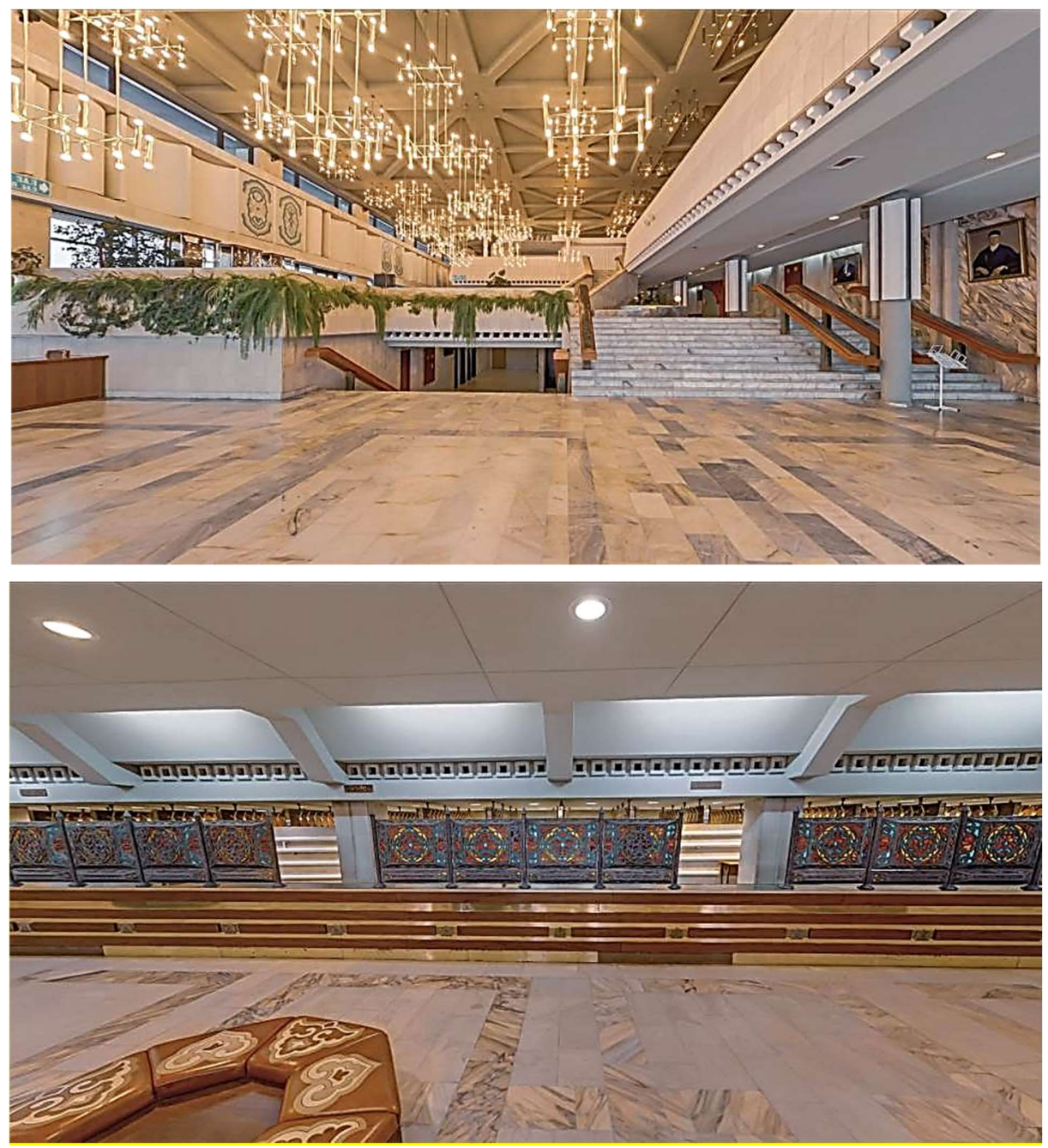

Fig. 7. Galiasgar Kamal Tatar State Academic Theatre. Interiors.
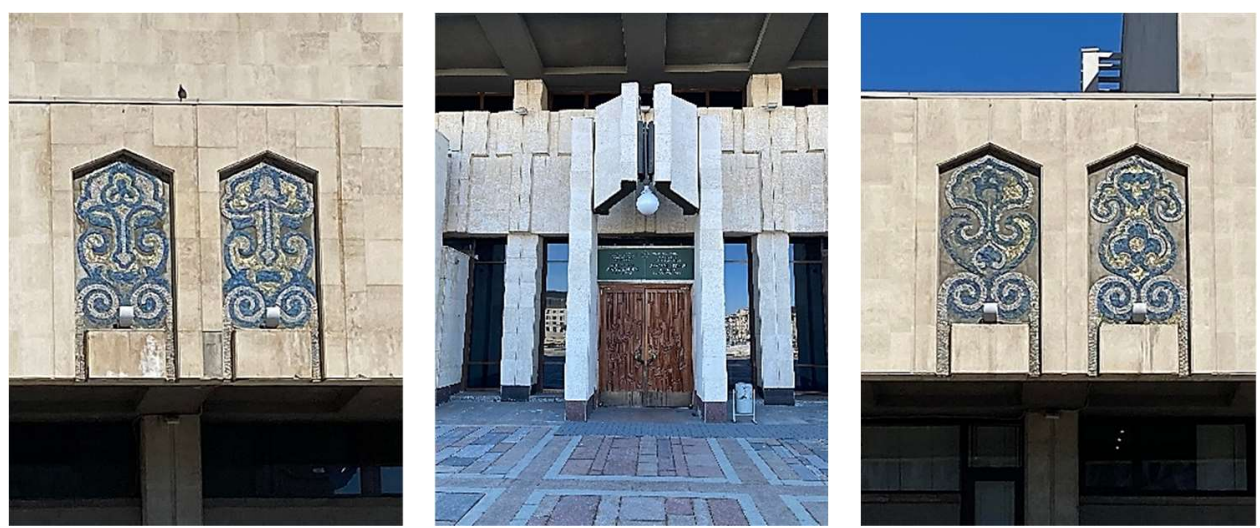

Fig. 8. Galiasgar Kamal Tatar State Academic Theatre. Details on the facade. 
The main accent in the theater's exterior is the sloping roof over the large hall, covered with turquoise glazed metal tiles, which make up a geometric ornament. In the design of the theater, the stylized 3rd ornamental complex (in the form of theatrical masks) is mainly used on mosaic inserts decorating the facade, as well as on repeating elements in the interior.

By the very end of the XX century, the emergence of another example of the appeal to national-regional traditions in the architecture of spectacular buildings took place. We are talking about the reconstruction of the building of the Saydashev State Great Concert Hall. The building of the concert hall was built in 1967 according to the project of architects M. Agishev and E. Agisheva in the contemporary style of modernism with a minimalistic «glass» facade. In 1996, the building was reconstructed according to the project of architects V. Loginov, E. Prokofiev and engineer V. Abramov, as a result of which it significantly changed its appearance. The building acquired the features of the postmodernism style with references to the motifs of Tatar monumental architecture in the composition of the facade and its individual elements, as well as interior design. The new imaginary solution of the concert hall building is more in harmony with the surrounding buildings and contributes to a more holistic perception of the ensemble of Svobody Square (Fig. 9).
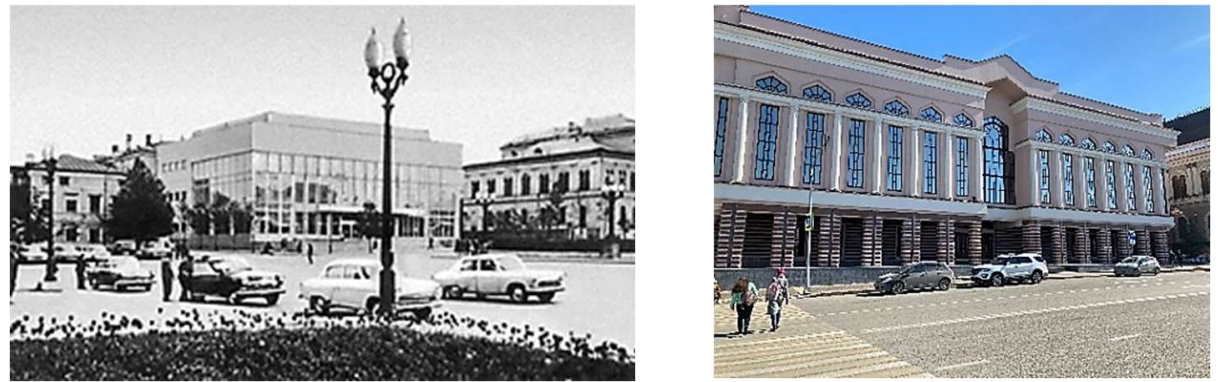

Fig. 9. Saydashev State Great Concert Hall. Historical photo and current state.

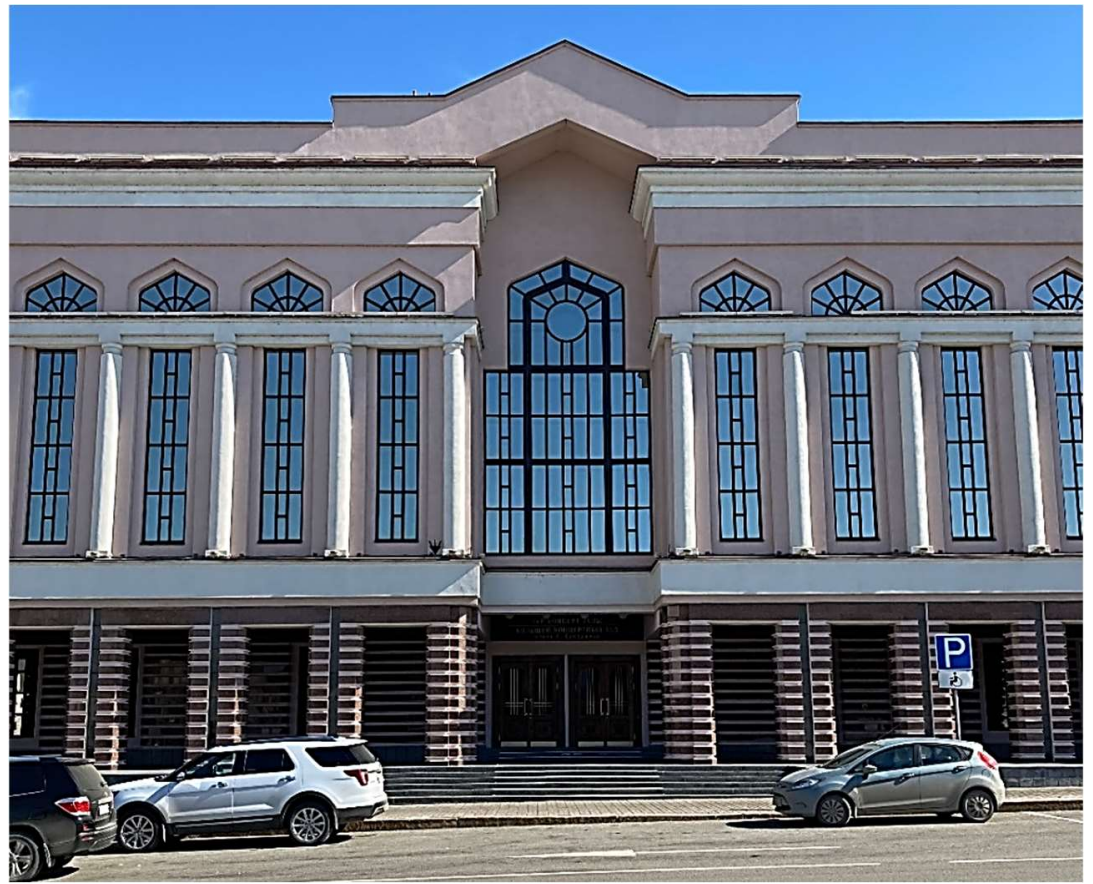

Fig. 10. Saydashev State Great Concert Hall. Fragment of the main facade. 
The creative method that guided the architects of the concert hall can be considered the principle of «symbiotic architecture», in which an architectural structure acquires a unique national and regional originality due to the inclusion of local «genetic and stylistic components» identified by the academician of architecture S.S. Aidarov [30]. Thus, an associative approach is implemented to the introduction of national and regional compositional techniques in the facade solution, as well as ornamental complexes in the interior decoration. The compositional solution of the facade of the concert hall building is based on a system of pointed arches and a central «portal» with a pointed end. Such a compositional technique makes the object related to the traditional monumental architecture of Tatarstan, the large glazing area, in turn, speaks of the modernity of the building (Fig. 10). The division of the glazing fragments is made in the form of a highly revised, simple geometric ornament. The corners of the building are emphasized by a rosette imitating a stalactite at the level of the gallery of the first tier, and a stylized ornamental element at the level of the attic. In the interior of the concert hall, mainly the 3rd and 6th ornamental complexes are used as a motif for decorating the walls with natural stone and painting on the ceiling. Ornamental complexes are significantly stylized (Fig. 11).
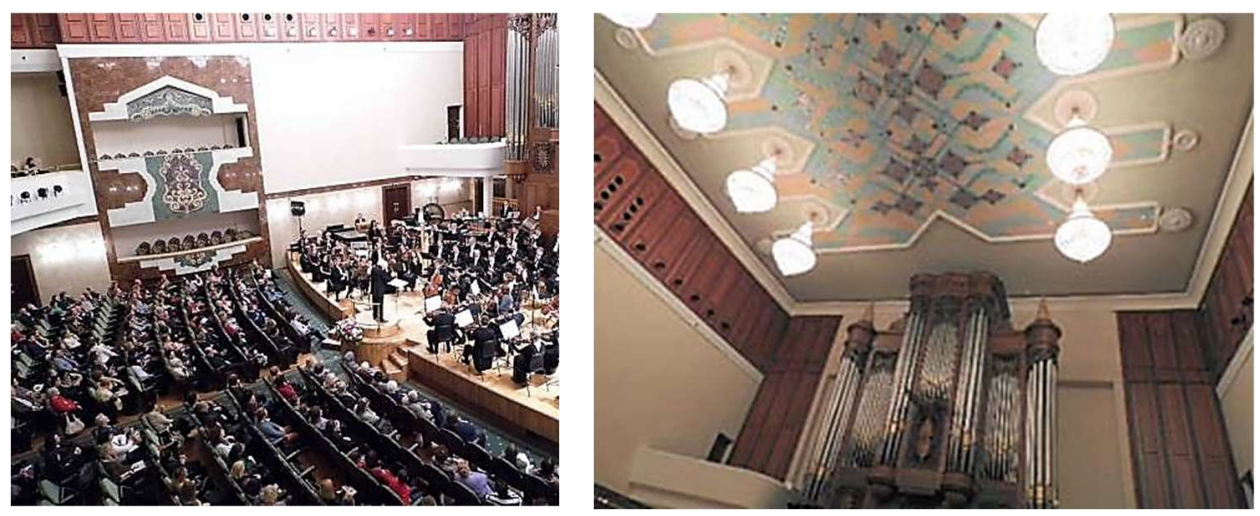

Fig. 11. Saydashev State Great Concert Hall. Interior.

\section{Conclusion}

As a result of the study, the main conclusions can be formulated:

1. The accent character of large spectacular buildings of the middle and the end of the XX century in the central part of the city, as a rule, is emphasized by the introduction of national and regional traditions.

2. Fragmentary use of ornamental complexes in the compositionally important parts of buildings allows to correctly introduce the national-regional component into their imaginary solution.

3. In the considered objects, various methodological approaches to the introduction of regional traditions are distinguished, corresponding to the tasks and stylistic characteristics of their time:

- In the Tatar Academic State Opera and Ballet Theatre named after Musa Dzhalil - plaster molding according to the author's drawings in compositionally important parts of the building;

- In Galiasgar Kamal Tatar State Academic Theatre - ceramics, majolica, architectural and artistic metal lattices, leather inlay;

- In Saydashev State Great Concert Hall - an associative approach to the introduction of national-regional compositional techniques in the facade solution - a combination of a system of pointed arches with a large glazing area. 
4. The architects of the middle and the end of the XX century laid the foundations of modern regional-national architecture and the methodology for the formation of a decorative-artistic system that combines the stylistic techniques of classicism, modernism, postmodernism with techniques which had references to the traditions of the Bulgar-Tatar Middle Ages.

\section{References}

1. S.Salvo. Conservation and modern architecture. Fortune and misfortune of the School of Mathematics at Rome University (G. Ponti, 1932-1935), Frontiers of Architectural Research, 4, 186-201 (2015). DOI: 10.1016/j.foar.2015.03.004.

2. M. Heldak, E. Gonda-Soroczynska. Historical Heritage and Space Transformation, IOP Conf. Series: Materials Science and Engineering 471, 112030 (2019). DOI: 10.1088/1757-899X/471/11/112030.

3. S. Bahga, G. Raheja. Complexities of practicing architectural regionalism in India: An interview study, Frontiers of Architectural Research 9, 568-578 (2020). DOI: 10.1016/j.foar.2020.03.003.

4. S. Bahgan, G. Raheja. An account of critical regionalism in diverse building types in postcolonial Indian architecture, Frontiers of Architectural Research 7, 473-496 (2018). DOI: $10.1016 /$ j.foar.2018.09.001.

5. G.N. Aidarova (Aidarova-Volkova). «Old» and «new» in the architecture of ancient Kazan - two wings of sustainable conservation and development of the historical center, Arhitektura i stroitel'stvo Rossii 3, 20-24 (2018).

6. T.S. Reshetnikova. Reconstruction of the remembrance: Palace of Culture in Slantsy Frontiers of Architectural Research 8, 572-590 (2019). DOI: 10.1016/j.foar.2019.06.004.

7. F. Lyu. Architecture as spatial storytelling: Mediating human knowledge of the world, humans and architecture Frontiers of Architectural Research 8, 275-283 (2018). DOI: 10.1016/j.foar.2019.05.002.

8. A.T. Nguyen, N.S.H. Truong, D. Rockwood, A.D.T. Le. Studies on sustainable features of vernacular architecture in different regions across the world: A comprehensive synthesis and evaluation, Frontiers of Architectural Research 8, 535-548 (2019). DOI: 10.1016/j.foar.2019.07.006.

9. H.M. Mazraeha, M. Pazhouhanfar. Effects of vernacular architecture structure on urban sustainability case study: Qeshm Island, Iran, Frontiers of Architectural Research 7, 11-24 (2018). DOI: 10.1016/j.foar.2017.06.006.

10. R. Mamun, R.A. Dilshad. Modernity in tradition: Reflections on building design and technology in the Asian vernacular, Frontiers of Architectural Research 4, 46-55 (2015). DOI: 10.1016/j.foar.2014.11.001.

11. G. Aidarova, E. Bashirova. Regional architecture of Russia: Kazan - conflicts of the «old» and «new», IOP Conf. Series: Materials Science and Engineering 890, 012016 IOP Publishing, (2020). DOI: 10.1088/1757-899X/890/1/012016.

12. K. Kiruthigan, K. Thirumaran. Visual perception on the architectural elements of the built heritage of a historic temple town: A case study of Kumbakonam, India, Frontiers of Architectural Research 6, 96-107 (2017). DOI: 10.1016/j.foar.2016.10.002.

13. S. Farhan, V. Akef, Z. Nasar. The transformation of the inherited historical urban and architectural characteristics of Al-Najaf's Old City and possible preservation insights, Frontiers of Architectural Research 9, 820-836 (2020) DOI: 10.1016/j.foar.2020.07.005.

14. L. Guerrini. Design as a Tool for Bringing New Life to the Historic Centre of L'Aquila G. Amoruso (ed.), Putting Tradition into Practice: Heritage, Place and Design, LNCE 3, 115-124 (2018). DOI: 10.1007/978-3-319-57937-5_90. 
15. Y. Xiao, Y. Wan, Ch.Q.L. Xue. Performing arts buildings in Taiyuan: Cultural history buildings in a second-tier Chinese city, Frontiers of Architectural Research 8, 215-228 (2019). DOI: 10.1016/j.foar.2019.03.007.

16. Z.A.A.E. Elmoghazy, H.M.N. Afify. Patterns: The crime that has become the haven in architectural practice, Ain Shams Engineering Journal 11, 823-838 (2020). DOI: 10.1016/j.asej.2019.12.002.

17. J. Romero. Architectural survey of historical buildings: The orders of classical architecture in the Baptistery of Florence, Frontiers of Architectural Research 10, 117 133 (2021). DOI: 10.1016/j.foar.2020.07.002.

18. M. Erbudak. Symmetry analysis of the floor ornaments of the San Marco cathedral in Venice, Heliyon 5, e01320 (2019). DOI: 10.1016/j.heliyon.2019.e01320.

19. M. D’Orazio, G. Bernardini, S. Tacconi, V. Arteconi, E. Quagliarini. Fire safety in Italian-style historical theatres: How photoluminescent wayfinding can improve occupants' evacuation with no architecture modifications, Journal of Cultural Heritage 19, 492-501 (2016). DOI: 10.1016/j.culher.2015.12.002.

20. U. Berardi, G. Iannace. The acoustic of Roman theatres in Southern Italy and some reflections for their modern uses, Applied Acoustics 170, 107530 (2020). DOI: 10.1016/j.apacoust.2020.107530.

21. G.N. Aidarova-Volkova. Architectural culture of the Middle Volga region 196, (2005).

22. Y. Abdullahin, M.R. Bin Embi. Evolution of Islamic geometric patterns, Frontiers of Architectural Research 2, 243-251 (2013). DOI: 10.1016/j.foar.2013.03.002.

23. M. Ahmada, K. Rashid, N. Naz. Study of the ornamentation of Bhong Mosque for the survival of decorative patterns in Islamic architecture, Frontiers of Architectural Research 7, 122-134 (2018). DOI: 10.1016/j.foar.2018.03.004.

24. F. Lu, Architecture as spatial-textile storytelling: Metamorphosis of frieze as a narrative medium mediating the Panathenaia festival, Frontiers of Architectural Research 5, 489-498 (2016). DOI: 10.1016/j.foar.2016.08.003.

25. F.H. Valeev. Kazan Tatars' ornament, Tatar. kn. izd-vo, Kazan, 204 (1969).

26. N.S. Kinosyan. A creative method of architect I.G. Gajnutdinov in ensemble of Tatar State Academic Theatre of Opera and Ballet named after Musa Jalil in Kazan, Izvestiya KGASU 2 (32), 41-47 (2015).

27. Archival photographs from the N.I. Lobachevsky Scientific Library of Kazan Federal University (the archive of rare books and manuscripts), Archive found, 20.

28. S.P. Sanachin. Excursion into the architectural life of the Soviet of Kazan, Foliant, Kazan, 238, (2014).

29. D.D. Efimov, I.A. Fachrutdinova. National and international component in the architecture of Tatarstan in the period of Soviet modernism 1955-1990, Izvestiya KGASU 1 (47), 7-17 (2019).

30. S.S. Aidarov. Tatarstan architecture: From the revival of traditions to future originality «Arkhitektura i stroitel'nyy kompleks Tatarstana», digest dedicated to the $1000^{\text {th }}$ anniversary of Kazan, 5-20 (2005). 